\title{
Evaluation OF Grand Teton NATIONAL PARK'S "BE BEAR AWARE" MESSAGE TO VISITORS
}

\author{
NANETte M. Nelson $\downarrow$ PATRICIA A. TAYlor $\downarrow$ Amy M. RieSER \\ UNIVERSITY OF WYOMING $\uparrow$ LARAMIE
}

\section{$\downarrow \quad$ AbSTRACT}

Grand Teton National Park (GRTE) receives nearly 4 million visitors a year. GRTE also supports thriving populations of black (Ursus americanus) and grizzly (Ursus arctos) bears (GRTE, 2007). The extent to which humans recreate in prime bear habitat influences the probability of bear-human encounters and the potential for conflict. In an effort to reduce bear-human encounters, GRTE managers initiated the "Be Bear Aware"(BBA) program in 2007. One objective of this program is to reduce bear-human encounters through proper food storage by visitors to the campground and picnic areas. To evaluate the efficacy of this program we proposed to interview a sample of park visitors to assess their knowledge and beliefs regarding proper food storage and recreating safely in bear country, gauge their recall of particular "Be Bear Aware" signage, and ascertain their perceived risk of a bear encounter. This information along with trip characteristics and visitor demographics will help park managers identify if "Be Bear Aware" messages are effective and for whom.

The project was divided into two phases. The first phase, reported on here, consisted of developing a survey instrument, preparing a sampling plan, and submitting the necessary paperwork to receive approval from the Office of Management and Budget (OMB) to conduct the research. Phase 2 of the project, to be initiated in the summer of 2010, consists of administering the survey, analyzing the data, and completing a final report summarizing our research findings.

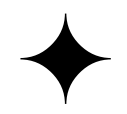

-

\section{$\uparrow \quad$ INTRODUCTION}

Every year nearly 4 million visitors view the extraordinary beauty of Grand Teton National Park (GRTE), the majority of whom visit during the peak summer season of June through September. Visitors marvel at the flora and fauna of the park, which are varied and extensive enough to provide habitat within GRTE for thriving populations of black (Ursus americanus) and grizzly (Ursus arctos) bears (GRTE, 2007).

The program of management for bears in the park is to sustain "free ranging, naturally regulated populations" of bears throughout the Park including the John D. Rockefeller, Jr. Memorial Parkway (GRTE, 2007). However, the extent to which humans recreate in prime bear habitat increases the probability of bear-human encounters and the potential for conflict. The park, therefore, endeavors to develop and implement wildlife management strategies that balance the needs of bears with visitor enjoyment, education, and appreciation of the park.

Every year for the last six years, there has been increasing human-bear contact, with six bears being destroyed because of human or food aggression (K. Wilmot, Bear Management Office, GRTE, personal communication, July 3, 2009). In 2007, GRTE recorded 210 bear-human confrontations and 56 bear-human conflicts ${ }^{1}$. If bears become habituated

\footnotetext{
${ }^{1}$ Confrontations are defined by the park as "incidents where bears approach or follow people, charge or otherwise act aggressively toward people, enter front-country developments, or enter occupied backcountry campsites without inflicting human injury." Bear-human conflicts are defined by the park as "incidents where bears damage property, obtain human foods, or injure people" (GRTE, 2007, p.1).
} 
toward human food and show no fear of humans, they are euthanized (GRTE, 2007).

In an effort to reduce bear-human encounters and potential conflicts, GRTE managers initiated the BBA program at the start of the 2007 season. The new program is an integrated strategy consisting of five elements: 1) public information and education; 2) removal of human food sources, 3) enforcement of food storage regulations, 4) management and control of problem bears, and 5) research. As part of the public information and education component, the park updated its bearrelated message. This included adoption of a universal theme BBA, designing new graphics to improve message visibility, wider display of the bear warning signs, and increasing visitor outreach efforts at the park's entrance and high-use areas. The current message emphasizes food storage, outlining a strict set of rules about what items should be stored (e.g., food, coolers, water bottles, utensils, etc.) and how to store items properly (i.e., in a bear box or a closed, locked vehicle with windows rolled up).

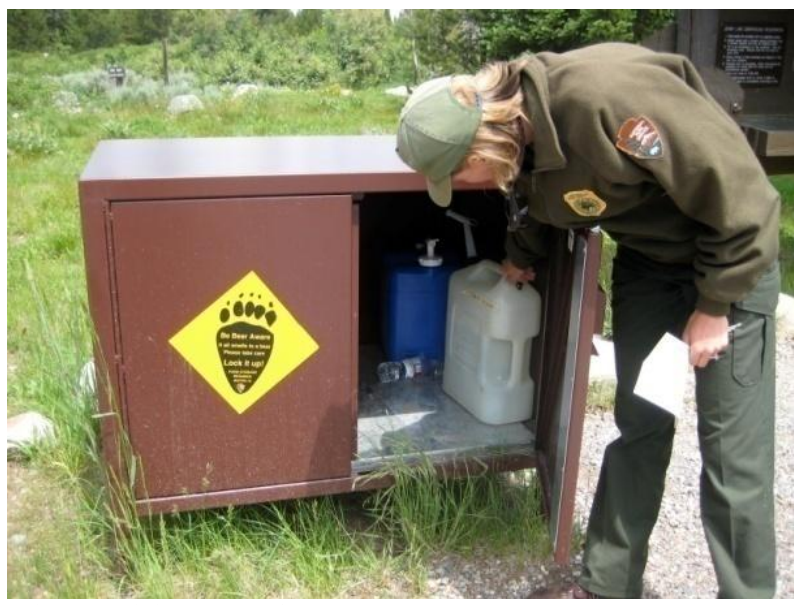

Photograph by A. M. Rieser.

The park also developed several guidelines on how to safely and recreate in bear country. These guidelines have been widely disseminated throughout the park including a full page in the Teewinot, the park's newspaper. The newspaper, handed to all park arrivals, gives information on food storage, behavior during a bear encounter, differences between black and brown bear, and safety on trails.

Despite these efforts park employees are still observing noncompliance with GRTE's food storage policy, resulting in more "problem bears," and requiring the allocation of limited resources toward managing problem bears. When bears actively seek sources of human food, property damage and injuries to humans may result. In the interest of protecting park visitors and preserving the park's bears, GRTE managers sought a formal evaluation of the public information and education portion of the BBA program.

\section{$\uparrow$ APPROACH}

To evaluate whether the information disseminated as part of the Be Bear Aware program is in fact reaching park visitors, and is effective, we proposed to interview a sample of campground visitors and picnickers who were observed complying with the Bear Aware message, and those who were observed to be non-compliers (e.g. leaving food on tables, around the campsite, etc.). The survey instrument will ask "compliers" and "non-compliers" to identify BBA messages, where these messages were displayed, and the meaning behind such messages. In addition we will be assessing park visitors' knowledge and beliefs regarding proper food storage and safely recreating in bear country as well as ascertaining their perceived risk of a bear encounter. This information, along with trip characteristics and a demographic profile of campground visitors will help park managers identify if BBA messages are effective and for whom.

Under the Paperwork Reduction Act of 1995, surveys of park visitors require federal approval from the Office of Management Budget (OMB). Although the National Park Service and OMB have an agreement to streamline this process, final approval was expected to take at least eight months. Therefore, the project was divided into two phases. The first phase, and the one being reported here, consisted of developing a survey instrument, preparing a sampling plan, and submitting the necessary paperwork to receive approval from OMB to conduct the research. Phase 2 of the project, to be initiated in the summer of 2010, consists of administering the survey, analyzing the data, and completing a final report summarizing our research findings. The remainder of this report covers the final survey instrument, the sampling plan, and submission of paperwork to receive federal approval.

\section{$\downarrow$ SURVEY DESIGN}

\section{Structure of the Survey}

The survey instrument consists of six sections: 1) Location and Visitation (trip characteristics), 2) Food Storage, 3) Beliefs about Food Storage, 4) Bear Aware Program, 5) Bear Aware and Safety, and 6) Demographics. 
Park managers have gone to considerable lengths to develop education materials for and provide information to the public as part of the $\mathrm{Be}$ Bear Aware program. Therefore, the questions in the sections on Food Storage and Beliefs about Food Storage (Sections 2 and 3) are designed to elicit visitors' actions as well as beliefs regarding proper food storage. Answers to these questions will inform park managers if their message is being seen, read, and/or heard, and whether park visitors are translating the Be Bear Aware message into the desired behavior (i.e., proper food storage, what to do when you encounter a bear). Because park managers are interested in message penetration, all park visitors to campgrounds and picnic areas are in the population universe to be sampled, whether they have food with them or not.

In addition, park managers are keenly interested in the message that is most salient to visitors to comply with park rules. To address the salience issue, we ask a series of questions on where visitors might have received information on recreating safely and responsibly in bear country (Section 4). We also include a set of questions asking park visitors if they remember seeing particular Be Bear Aware signs, where they remember seeing the signs, and how many times (Section 5). Finally we ask visitors to tell us which of the messages had the greatest impression (Section 5). We allow that information obtained outside of the park (e.g., a television program, talking with friends or family members) may have been the most influential in a visitor complying with park regulations. Knowledge of bears acquired elsewhere is still useful to the GRTE managers in that the format (e.g., verbal or video) and/or content (e.g., a friend's experience, a bear's life history) could be incorporated into future educational efforts.

Previous research on human-bear interactions in Yosemite National Park found that bear-related messages targeted at visitors' beliefs about perceived risk of human-bear interactions are most effective (Lackey and Ham 2003). A second study in New York's Adirondack Park suggested that risk perception influences visitors' beliefs and attitudes and thus their receptivity toward educational messages (Gore et al. 2006 \& 2007). One factor identified as influencing visitor risk perception is frequency of bear encounters while camping in the park (Gore et al. $2006 \&$ 2007). We address risk perception by asking visitors how strongly they agree or disagree with the statement: "it is very unlikely that a bear will enter this campground or picnic area while I am here" (Section 5). We believe, based on research by others, that visitors who strongly agree with this statement will be less inclined to follow park regulations. If true, park managers may want to emphasize the likelihood of encountering a bear while visiting GRTE in their educational materials to obtain higher rates of compliance.

Furthermore, the Yosemite National Park study found experienced park visitors believe they "know about bears" and that familiarity tends to lessen perceived risk if the visitors' own direct experience lacked negative bear encounters (Lackey and Ham 2003). Based on the results of the Yosemite National Park study, we will ask visitors to recall their own past experience with bears or relate a story that was told to them (Section 5). Of primary importance is ascertaining whether the visitors' encounter was negative; therefore, we will probe the visitors to reveal if they (or the person in the story) felt concerned for their safety or their personal property. We believe visitors who have prior knowledge of or experience with a bear that led to a negative outcome will be more likely to follow park regulations.

Trip characteristics and demographic data (Sections 1 and 6) will allow us to identify particular sub groups (e.g., campers at group sites, perennial visitors to GRTE) that may need additional education and follow-up to obtain compliance with park rules. In particular, we will identify visitors who were observed complying with the Be Bear Aware message, and those who were observed to be noncompliers (e.g. leaving food on tables, around the campsite, etc.). We will evaluate whether compliance status is associated with knowledge and behavior in bear country, past bear experience, trip characteristics, and demographic data. The results of this analysis will be essential to park managers in their efforts to design a public information and education campaign that approaches $100 \%$ compliance.

\section{Pre-Testing: NPS Discussion Group and Public Focus Group}

We conducted two separate information sessions intended to clarify wording of questions in the survey instrument and to ensure the survey covered the salient topics related to the BBA program. The first discussion group comprised 10 park and concession employees representing various service sectors within the park including law enforcement, field biology, backcountry permits, custodial, maintenance, interpretation, concessions, administration, and business resources. The focus 
group comprised seven citizens from the adjacent town of Jackson Hole. Potential participants were recruited through an advertisement in the local newspaper and a flyer posted at the public library. The final list of participants was selected for demographic diversity based on a short set of screening questions asked of those who responded to the ad by phoning the toll-free number provided.

At the beginning of the information sessions, meeting participants completed the thencurrent draft of the questionnaire, which served as the focal point for the ensuing discussion. Taylor and Nelson, with the assistance of Rieser, served as the facilitators for both discussions. Both the discussion group and the focus group, each about two hours in duration, were held on July 7, 2009. Light refreshments were served at both sessions, and participants at the public focus group were compensated $\$ 50$ each.

The questionnaire also benefitted from several discussions with our collaborators at GRTE, Kate Wilmot, from the park's Bear Management Office, and Sue Consolo-Murphy, Chief of Science and Resource Management.

\section{$\uparrow \quad$ Sampling Plan}

\section{Sampling Frame}

To evaluate the efficacy of the park's BBA message we will conduct intercept interviews with a sample of park visitors in the summer of 2010. At the park's request we will only assess attitudes and behaviors of front country users; therefore, survey administration will be limited to campground sites and picnic areas. There are approximately 1,165 campsites and another 100 picnic sites in the initial potential universe of contacts. We expect that nearly all the sites which are occupied will have at least one adult (age 18 or older) member who has not previously completed this survey. Our target for completed interviews is 625 yielding a margin of error of $\pm 4 \%(\mathrm{ME}=1 / \sqrt{ } \mathrm{n} \times 100)$ for sample estimates of the population's true value.

We will be conducting interviews during peak summer months (June through August), therefore we expect that on average $97 \%$ of the campsites and $60 \%$ of the picnic sites will be occupied. Campers occupy a site on average for two nights, while picnickers are replaced each day. We will be interviewing fifteen days over a 20 day period, which means that there are potentially 8,475 camper site occupations $[(20 \div 2) *(15 \div 20) *(0.97$ $* 1,165)=8,475]$ camping site occupations. For picnickers, the equivalent number of sites is 900 picnic site occupations $[(0.60 * 100) * 15$ days $=900]$. Since we want approximately 625 completed surveys, and approximately $10 \%$ of all sites are picnic sites, we will take completed interviews from 63 picnic sites.

Picnic sites are quite varied and are generally a grouping of four to six tables at sites along the major road ways in GRTE. There are, however, two large picnic areas, one at String Lake and a second at Colter Bay, each having approximately twenty-four tables. We will take 12 completed interviews at both String Lake and Colter Bay picnic areas, and three to four each at the other eight picnic sites. Additionally, there are scattered tables for eating outside several of the camp stores including Colter Bay, Leeks Marina, and Flagg Ranch. We will finish our picnic interviewing with these sites.

The sampling numbers for the initial potential universe of camping contacts will use the average proportion of occupied sites by size of the campground. We will need approximately 562 completed interviews from campers. The campgrounds and the associated estimates of occupancy and the number of campground sites to sample are presented in Table 1.

\section{Survey Administration}

The procedure for collection of information will be an intercept interview. We expect to use scannable forms for recording interviews to aid in the transfer of answers from paper to an electronic data file. We have established a goal of 625 completed interviews (2.5 per hour, six hours of interviewing per day, 5 days each week $=75$ per week per interviewer). Three interviewers working three weeks each would yield 675 completed interviews.

A very simple sampling procedure will be followed, stopping at every $4^{\text {th }}$ site to intercept an occupant for the survey. This should space out the campers in the sample, such that parties traveling together and perhaps camping side by side, are not all included in the sample. Since the campgrounds are used as a home base for exploring the park, many of the sites will be unoccupied by the time we can sample. Therefore, we will stop at the next site occupied after the fourth site. Additionally, the interviewers will attempt to alternate between a male 
and female respondent at each campsite and picnic site.

The physical layout of the campgrounds varies, with several campgrounds using one long circular road, while several others have several road loops stemming out from the main road. Where the campgrounds are organized in loops, the loops themselves will be randomized so that the interviewer may start in loop 3; move to loop 7; then to loop 2, etc. For these loops, the interviewer will attempt to interview at every fourth campsite of the beginning loop. For the second loop, the interviewer will begin the interviewing at the second campsite and then move four campsites. Every loop will add one campsite to the start of the interviewing. These alternations will help to randomize the selection of campsites, and will prevent shared experiences in the campground from affecting respondents; therefore, the chance that respondents who are traveling together would be selected will be minimized. Should the interviewer completely traverse a campground before the end of the three week interviewing period, sampling will begin at the starting loop plus 1 (e.g. loop 4, loop 8, loop 3), with the fifth campground or picnic site; then in the second loop; the ninth site, etc.

Additionally, for those selected sites where no one is available (e.g. the party has left for sightseeing for the day), the interviewer will return in the late afternoon to attempt an interview. Therefore, we should reduce the likelihood of bias from those parties who are more likely to spend time away from their campsite. These visitors may be young adults without children, and hence, may have different attitudes and knowledge regarding food storage and the BBA program.

\section{Expected Response Rate}

Intercept interviews in the National Parks tend to have very high cooperation and completion rates - on the order of 90-92\%. For example, our survey at Rocky Mountain National Park completed in 2003-2004, had a completion rate of 93\%. We expect a similar completion rate (as defined by the American Association of Public Opinion Research (AAPOR) standards). The AAPOR standards require that the completion rate be based on the number of respondents in the sample, whether they were at the campsite and were directly contacted by the interviewer. Therefore, if a campsite is occupied but the interviewer is never able to contact the campers, these campers are still part of the total (the denominator) in the computation of the completion rate.
Table 1. GRTE Campgrounds and Proposed Sampling Effort

\begin{tabular}{|c|c|c|c|c|c|}
\hline Campground & $\begin{array}{c}\# \text { of } \\
\text { Campsites } \\
\text { as of } 2009\end{array}$ & $\begin{array}{l}\text { Usual \% of } \\
\text { Occupancy }\end{array}$ & $\begin{array}{l}\text { Usual \# of } \\
\text { Occupied } \\
\text { Sites }\end{array}$ & $\begin{array}{c}\text { As a } \% \text { of } \\
\text { all } \\
\text { Occupied } \\
\text { Sites }\end{array}$ & $\begin{array}{c}\text { \# of } \\
\text { Sampled } \\
\text { Sites }\end{array}$ \\
\hline Gros Ventre & 392 & $96 \%$ & 376 & 33.3 & 187 \\
\hline Jenny Lake & 50 & $100 \%$ & 50 & 4.4 & 25 \\
\hline Colter Bay & 390 & $100 \%$ & 390 & 34.5 & 194 \\
\hline $\begin{array}{l}\text { Signal } \\
\text { Mountain }\end{array}$ & 86 & $96 \%$ & 83 & 7.3 & 41 \\
\hline Lizzard & 60 & $92 \%$ & 55 & 4.9 & 28 \\
\hline Flagg Ranch & 171 & $98 \%$ & 168 & 14.8 & 83 \\
\hline $\begin{array}{l}\text { Grassy } \\
\text { Meadows }\end{array}$ & 16 & $50 \%$ & 8 & 0.7 & 4 \\
\hline Total & 1165 & $97 \%$ & 1130 & 100.0 & 562 \\
\hline
\end{tabular}

Potential Non-Response Bias

Additionally, although we expect high cooperation and completion rates, there nonetheless may be campers or picnic visitors who for reasons of privacy or time cannot cooperate in the study. We will therefore move to the demographic questions and ask the visitor only their state of residence, education, and age, in order to compare the respondent group with non-respondents. By having age and education, we will be able to estimate some bias in the response of the completed surveys. By having state of residence, we can also estimate a bias which might occur due to a local attachment to the park.

\section{$\uparrow \quad$ FEDERAL APPROVAL}

The final deliverable for this project was the submission of all forms and materials (including a final questionnaire) required for approval of the survey by OMB. The final questionnaire and sampling plan (described in the previous two sections) along with a statement of justification were submitted to OMB in September 2009. Our submission is currently under review and we expect to receive approval to conduct our survey in the spring of 2010.

\section{ACKNOWLEDGEMENTS}

We would like to thank Kate Wilmot and Sue Consolo-Murphy for their assistance in developing our survey instrument including a tour of the park's campgrounds and picnic areas and arranging the focus group of park and concession employees. This research was funded by a UW-NPS research grant awarded to P. A. Taylor and N. M. Nelson and GRTE's Bear Project. This manuscript is a contribution to the University of Wyoming /National Park Service Research Station. 


\section{$\uparrow \quad$ Literature Cited}

Gore ML, Knuth BA, Curtis PD, Shanahan JE. 2006. Stakeholder perceptions of risk associated with human-black bear conflicts in New York's Adirondack Park campgrounds: Implication for theory and practice. Wildlife Society Bulletin, 34:36-43.

Gore ML, Knuth BA, Curtis PD, Shanahan JE. 2007. Campground manager and user perceptions of risk associated with negative human-black bear interactions. Human Dimensions of Wildlife 12: 31-43.
Grand Teton National Park. 2007. 2007 Wildlife Management: Human-Bear Conflicts. Available from:http://www.nps.gov/grte/planyourvisit/uplo ad/FINAL_2007_human-ear_conflicts_brief.pdf

Lackey BK, Ham SH. 2003. Final report: Human element assessment focused on human-bear conflicts in Yosemite National Park. Moscow, Idaho: University of Idaho. 